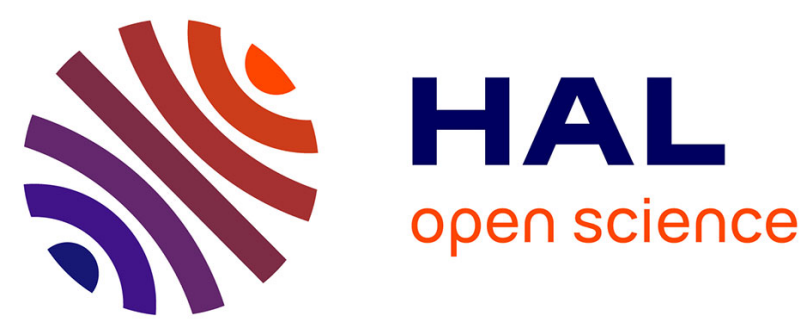

\title{
World TRIZ Sites Project (WTSP) (2): To Build Catalogs of TRIZ-Related Web Sites in the World
}

Toru Nakagawa, Darrell Mann, Michael Orloff, Simon Dewulf, Simon Litvin, Valeri Souchkov

\section{- To cite this version:}

Toru Nakagawa, Darrell Mann, Michael Orloff, Simon Dewulf, Simon Litvin, et al.. World TRIZ Sites Project (WTSP) (2): To Build Catalogs of TRIZ-Related Web Sites in the World. 19th International TRIZ Future Conference (TFC), Oct 2019, Marrakesh, Morocco. pp.508-525, 10.1007/978-3-03032497-1_40 . hal-02905537

\section{HAL Id: hal-02905537 \\ https://hal.inria.fr/hal-02905537}

Submitted on 23 Jul 2020

HAL is a multi-disciplinary open access archive for the deposit and dissemination of scientific research documents, whether they are published or not. The documents may come from teaching and research institutions in France or abroad, or from public or private research centers.
L'archive ouverte pluridisciplinaire HAL, est destinée au dépôt et à la diffusion de documents scientifiques de niveau recherche, publiés ou non, émanant des établissements d'enseignement et de recherche français ou étrangers, des laboratoires publics ou privés. 


\title{
World TRIZ Sites Project (WTSP) (2): To Build Catalogs of TRIZ-related Web Sites in the World
}

\author{
Toru Nakagawa ${ }^{1}$, Darrell Mann ${ }^{2}$, Michael Orloff ${ }^{3}$, Simon Dewulf $^{4}$, Simon Litvin $^{5}$, \\ and Valeri Souchkov ${ }^{6}$ \\ ${ }^{1}$ Osaka Gakuin University, 3-1-13 Eirakudai, Kashiwa, Chiba 277-0086, Japan \\ ${ }^{2}$ Systematic Innovation Network, Bideford, UK \\ ${ }^{3}$ Academy of Instrumental Modern TRIZ, Berlin, Germany \\ ${ }^{4}$ AULIVE, Glen Elgin, Australia \\ ${ }^{5}$ GEN TRIZ, LLC., Newton, MA, USA \\ ${ }^{6}$ ICG Training \& Consulting, Enschede, Netherlands \\ nakagawa@ogu.ac.jp
}

\begin{abstract}
.
We started the World TRIZ Sites Project (WTSP) in Dec. 2017 for the purpose of building catalogs of TRIZ-related Web sites in the World. Getting support by a number of TRZ colleagues, we started the project to achieve by voluntary cooperation of many (hopefully about 100) TRIZ colleagues coming from various countries. Our basic strategy was to build Country WTSP Catalogs in each country first and then build World WTSP Catalogs by using selected sites. Japan WTSP Catalog was made and posted in English in Apr. 2018 as an example. Internet surveys of TRIZ sites located in each country were shown for 33+ countries. Adding new members at TFC2018, we got over 70 voluntary members from $30+$ countries. But the actual WTSP work in individual countries is proceeding only slowly till recently.

So we started Top-down approaches using Internet surveys in global scale, for TRIZ sites written in several major languages, and for sites around TRIZ by using different keywords in wider scopes. We also realized the importance of showing concrete images of our World WTSP Catalogs and practical processes for achieving it. Thus we proposed an 'Ideal image' in the form of WTSP Database System and turned it into a simple and feasible structure. Our World WTSP Catalogs is made as a small Web site, which has 'Table of sites' (or Index) page(s) and many 'Descriptions of sites' pages, where many hyperlinks flexibly connect individual sites from the Index to the Description. Japan WTSP Catalog (for people in Japan) was rebuilt into World WTSP Catalog (Japan Part) (for people in the world). Practical Guide for Teams to build the World WTSP Catalogs is shown with templates and easy processes based on a new strategy "to list up and describe highly recommendable sites only in each country and to build the World WTSP Catalogs as soon as possible”.

We are going to report the draft version of World WTSP Catalogs at TFC2019. Getting Country Editors in every country is the crucial issue.
\end{abstract}


Keywords: World TRIZ Sites Project (WTSP), Global collaboration, TRIZ information resources, Catalog of TRIZ-related Sites, World WTSP Catalogs.

\section{Introduction: Our Aims and Plans}

This is the second report of the World TRIZ Sites Project (WTSP) [1] which was started in December 2017 [2]. The purpose of the project is to make the information sources on TRIZ and related methodologies viewable easily at the global scale.

For these three decades, TRIZ has been proliferated widely beyond ex-USSR across the world. A lot of activities, achievements, and knowledge of TRIZ have been accumulated, to the extent that their overview is not easily obtainable. There are many TRIZ-related Web sites in the world, but they are working separately and competing against one another. Ordinary Internet searches for TRIZ give messy/noisy outputs to hide valuable information. In this situation, interests in TRIZ in the world seems decreasing gradually even at the era when innovations are wanted everywhere.

As a solution to improve the situations, we have chosen to survey and build catalogs of TRIZ-related Web sites in the world. Web sites usually post various information publicly in the up-to-date form and are accessible freely from anywhere in the world.

The aims of the WTSP project are shown in Fig. 1 [3].

\section{[2] Aims of WTSP}

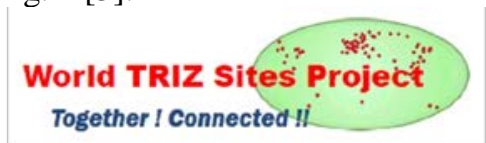

- To build Catalogs of TRIZ-related Sites

- of each country (in their own language, then in English) and

- of the whole world (in English, then in many languages)

- with appropriate (brief but close) introduction of individual sites

- with appropriate selection of (useful and important) sites

- for various people (unfamiliar, beginners, users, and experts in TRIZ)

- in the field of TRIZ and relevant methodologies

- as reliable sources of information (on theories, applications, activities)

- To keep the Catalogs up-to-date

- accepting new and revised information regularly

- revising all the Catalogs every two years

- For promoting TRIZ and relevant methodologies further in the world

- By voluntary collaboration of many TRIZ colleagues in the world

Fig. 1 Aims of the WTSP project [3]

For achieving these aims, we set up our working plan as shown in Fig. 2. 


\title{
[4] Plan of the WTSP Project
}

\author{
Working Plan \\ 1. In every country, to get voluntary members and form a WTSP team with a Country Editor. \\ Please send Membership Application Form to the WTSP Project Leader (T. Nakagawa). \\ 2. To survey TRIZ-related sites, visit the sites one-by-one and describe introductions. \\ Preliminary Internet Searches have been done for $33+$ countries. (noisy \& insufficient). \\ Contributions of site introductions should be encouraged for site owners. \\ WTSP members should prepare for the introductions of (all) significant sites. \\ 3. To compile a WTSP Catalog of TRIZ-related Sites in each country. \\ First in their own language. ==> Useful for people in the country. \\ Then in English (translation) of selected sites. ==> For the people in the world. \\ 4. To edit the World WTSP Catalog by integrating WTSP Catalogs of various countries. \\ To review and revise the documents by many members in the world, in parallel. \\ 5. To publicize the completed WTSP Catalogs for open, public use. (in many countries) \\ World Catalog (in English) and Catalogs of individual countries (in English and other). \\ 6. To translate the World WTSP Catalog into languages of various countries, \\ and to publicize them in each country (to see the world in their own languages).
}

Fig. 2 Working plan for the WTSP project [3]

As shown in these figures clearly, we take the bottom-up approach to build the Catalogs of TRIZ-related Web sites of individual countries first and then to build the Catalog of the whole world. Various Web sites in different languages can be introduced best by the people in the country (i.e., not by foreigners nor by robots), so we need a number of people in each country. And we have chosen to carry out all the work on voluntary basis, as a symbol of collaboration of the global TRIZ community.

Many TRIZ colleagues supported the idea of WTSP. But the difficulty of the project is clear from the beginning. Talented, active TRIZ people are very busy to work in their own business, and hence they can spend only little time squeezed in their busy schedule. Thus our TRIZ solution was to divide various tasks into small ones which can be carried out by many people in parallel. This solution works well only with high motivation of people, clear instructions and proper coordination by some coordinators. [1]

\section{Activities and Achievements in the First Year (2018) [1]}

\subsection{Organizing the WTSP project}

The idea of WTSP was proposed by Nakagawa in Nov. 2017 in private communications and also in his several draft proposals to about 100 TRIZ leaders/colleagues in the world (on the basis of his networks of “TRIZ Home Page in Japan” readers). Having got support by a number of TRIZ colleagues, he started the project in Dec. 2017 and sent invitations to them showing basic policies, aims, plans, guidelines, etc. [2]. His Web site "TRIZ Home Page in Japan" (THPJ) [4] served as the hub for the 
WTSP project where all the relevant information, documents, communications, etc. are posted regularly and openly.

WTSP is open to anybody who volunteers to work for its aims in collaboration. And it expects to have Country Editors in every county and several Global Co-editors at the global level. About 30 people from various countries expressed their support but only 10 of them submitted the Membership Application Form. Having obtained 5 Global Co-editors, we sent the WTSP Appeal [5] in Jun. 2018.

\subsection{Guidelines and Platform}

Nakagawa's experiences of making "Extended 100 TRIZ Links (with annotation) in Japan" and "Extended 120 TRIZ Links (with annotation) in the World" (2008) [6] formed the basis of practical process. In order to handle a few hundred of Web sites, Guidelines and a Platform were prepared. A standard form in Excel sheet for describing an individual site, another form in Excel for a list of sites in each country, coding rules of file names, a standard process of documentation and reviewing in the project, etc. were set.

For allowing parallel and cooperative work by a number of project members, a platform was prepared using the Bitrix24.com Standard Plan. It is an In-Cloud groupware system, accepting unlimited number of users (without per-user charge), providing documentation facilities with freely customizable folder system and version control, allowing easy communication among the members, having nice user interfaces and various support of instructions. So it looks very useful and powerful for cooperative work by many members.

\subsection{Pilot project to build Japan WTSP Catalog}

It is most important to perform a pilot project and show a good example as a model. Thus Nakagawa started to survey TRIZ-related sites in Japan and to make a Catalog. Since all the TRIZ-related Web sites in Japan are written in Japanese (and only a few of them have English pages as well), the survey and description were started in Japanese in mid Jan. 2018.

The Yahoo!.Japan search engine (instead of Google) was selected, because its option "displaying only one representative page for each site, and forming URL for the internal search of the site" is very useful. The search was made with the Keyword TRIZ, giving 400 sites displayed. The output on the browser was Copy \& Pasted onto an MS Word file keeping the hyperlinks active. The sites were visited one by one, to see the output page, the top page, the 'About us' page, and some more main pages. The site name, site domain URL, owner of the site, the role, special features, etc. were detected. With these information (together with background knowledge), introduction of the site was described in 3 to 10 lines and evaluated roughly (either important, worthy of listing, or irrelevant/no listing). In this manner about 70 sites were selected from the outputs. By use of his background knowledge he selected about 20 more sites of relevant methodologies and functions around TRIZ. 
Finally a Catalog of 92 TRIZ-related sites in Japan was built in Japanese for Japanese users in mid Mar. 2018, where the sites are categorized with their roles (including 24 selected sites as the role of (a) TRIZ information sending sites). The Japan Catalog was then translated into English with full introduction for the 24 selected sites and brief introduction for other 68 sites [7]. It was found that about half of the sites listed in 2008 have gone or inactive and about 2/3 of the 92 sites have emerged after 2008.

Through this pilot project, it was recommended for the practice of surveying and site description at the early stages that we should better use free format in MS Word rather than the formal formats in Excel. The experiences, knowhow, and results of this pilot project were reported in detail in THPJ [8].

\subsection{Preliminary Internet Searches in Various (33+) Countries}

Despite showing the results of Pilot project in Japan (Jan. - May, 2018) [8] and the WTSP Appeal [5] (Jun. 2018), the WTSP project did not start smoothly in various countries. There were communications from individual persons from time to time mentioning their own sites or some trials of surveys. Team activities did not start at any country. In such a situation we prepared for the paper presentations by the 6 Global Co-editors at Japan TRIZ Symposium (Sept. 2018) and at ETRIA TFC2018 [1].

For the purpose of initializing the survey activities in various countries, Nakagawa started the Preliminary Internet Searches of TRIZ-related sites in various countries. The searches were carried out by specifying the (target) site location to be individual country (intending to make a Catalog of each country). Keyword is TRIZ or ТРИЗ. The site language is taken various ways such as any language, English, Russian, French, German, etc. depending on the countries. Yahoo!.Japan search engine was used as before for using advantage of the special option. The outputs on the browser were Copy \& Pasted onto MS Word with active hyperlinks. Many sites, ranging 20 to 100 in number, are listed in the outputs (sometimes including apparently irrelevant sites, mostly due to a female singer's name Triz). Such results in Word, with the note of search conditions, were sent to the relevant people in each country and posted publicly in THPJ [9]. Table 1 summarizes the search results for the 33+ countries.

Table 1 Results of Preliminary Internet Searches for individual countries [9]

\begin{tabular}{|l|l|}
\hline Region & Country (outputs sites - irrelevant sites) \\
\hline A. Europe & Austria (55 - 5), Belgium (51 - 14), Switzerland (48 - 12), \\
& Czechoslovakia (67 - 8), Germany (95), Denmark (33 - 11), \\
& Spain (79 - 37), Finland (33 - 3), France (76), Italy (76), \\
& Netherlands (67 - 9), Norway (32 - 25), Poland (76 - 11), \\
& Portugal (82 - 62), Sweden (33 - 6), UK (68) \\
\hline B. Russia & Russia (100), \\
\hline C. Mid-East & Any in Arabic language (55), Iran (72 - 1), Turkey (80 - 1) \\
\hline D. Asia & China (82)(62 - 6), Taiwan (28), Indonesia (40 - 13), \\
& Japan (finished), Korea (72 - 4), Thailand (37 - 7) \\
\hline
\end{tabular}




\begin{tabular}{|l|l|}
\hline E. Oceania & Australia (42 - 11) \\
\hline $\begin{array}{l}\text { F. North } \\
\text { America }\end{array}$ & Canada (59 - 19), \\
USA (English 86 - 11; Russian 61; Ger. Fr. It. Sp. 65 - 20) \\
\hline $\begin{array}{l}\text { G. Central \& } \\
\text { South America }\end{array}$ & Argentina (52 - 33), Brazil (96 - 59), \\
\hline H. Africa & Any in Arabic language (55) \\
\hline
\end{tabular}

\subsection{Presentation and Appeals at ETRIA TFC2018}

The ETRIA TRIZ Future Conference 2018 at Strasbourg on Oct. 29-31, 2018 was a nice chance for promoting WTSP. We, in the name of the 6 Global Co-editors, presented a full paper [1]. And we prepared a Summary edition of 8 slides printed on both sides of an A4 paper [3]. Getting a desk at a corner of the hall, Nakagawa talked with many participants one by one to invite them to join WTSP. About 40 participants signed in the sheet stating to join WTSP as a Member. This pushed the WTSP project to a new stage with about 70 Members (including Members to be).

\section{Activities and Achievements in the Second Year (till May 2019)}

\subsection{Setting Up a Concrete Goal and Bottom-up Activities}

Just after the TFC2018, we set up a concrete goal "To report the completion of the World WTSP Catalogs (2019) at ETRIA TFC2019 (in Oct. 2019)”. For achieving the goal, we set up the time schedule as follows:

- Dec. 31, 2018: Formation of WTSP Teams in every country

- Mar. 31, 2019: Completion of Country WTSP Catalogs in every country, for open reviewing inside the project; First draft of Categorized World WTSP Catalog

- Jun. 30, 2019: Completion of revised Country WTSP Catalogs and Completion of World WTSP Catalog for open reviewing inside the project

- Sept. 20, 2019: Completion of revised World WTSP Catalogs and revised Categorized World WTSP Catalog for open public reviewing

WTSP Letters were sent from time to time to Members, Members to be, and Invitees of WTSP to inform about the TFC presentations, welcoming new Members (to be), plans and time lines, results of Preliminary Internet Searches, Invitation to WTSP, Practical ways to form WTSP Teams in each country, Tasks for surveying Sites, etc. We expected that the WTSP project was starting their activities in various individual countries, along the bottom-up process for building the Country Catalogs and then the World Catalogs.

Actually, however, the process of forming the WTSP Teams in individual countries did not start smoothly. Many of the people who stated to join WTSP at 
TFC2018 did not submit the Membership Application Form. In mid Jan. 2019, WTSP posted in THPJ its List of Members having 78 Members (including about 40 Members to be) from 29 countries/areas. Country Editors were assigned in 10 countries, i.e., Austria, Czech Rep., Spain, France, Portugal, Iran, China P.R., Japan, Malaysia, and Brazil. Some preliminary activities were reported in France and Germany. Team formation was especially difficult in the two important countries, Russia and USA, because of their big activities in TRIZ.

\subsection{Top-down Surveys of TRIZ-related Sites in the world}

The bottom-up activities in various countries seemed to be very weak even in late Mar. 2019, near the scheduled date for the completion of Country WTSP Catalogs. For supporting the activities from a different side, Nakagawa started Internet Surveys in the top-down direction [10]. TRIZ-related sites in the world were surveyed without specifying the site location, but specifying the site languages. The results are summarized in Table 2.

Table 2 Results of Internet Surveys in the global scale [10]

\begin{tabular}{|c|c|c|c|c|}
\hline Case & $\begin{array}{l}\text { Site loca- } \\
\text { tion }\end{array}$ & $\begin{array}{l}\text { Site } \\
\text { language }\end{array}$ & Keywords & Sites found (with evaluation) \\
\hline$(2 \mathrm{~A})$ & World & English & TRIZ & ( ) 6, $\bigcirc 13, \square 29, \triangle 33,-25$ \\
\hline (2B1) & \multirow{3}{*}{ World } & \multirow{3}{*}{ Russia } & \multirow{3}{*}{ ТРИЗ } & 106 sites \\
\hline$(2 \mathrm{~B} 2)$ & & & & $\begin{array}{l}26 \text { selected professional sites } \\
+49 \text { user pages }\end{array}$ \\
\hline (2B3) & & & & $\begin{array}{l}35 \text { selected professional sites } \\
+73 \text { user pages }\end{array}$ \\
\hline$(2 \mathrm{C})$ & World & German & TRIZ & 107 sites, -7 sites \\
\hline (2D) & World & French & TRIZ & 90 sites,-8 sites \\
\hline$(2 E)$ & World & $\begin{array}{l}\text { Spanish/ } \\
\text { Portuguese }\end{array}$ & TRIZ & 50 sites, -73 sites \\
\hline$(2 \mathrm{~F})$ & USA & English & TRIZ & ( ) 6, $\bigcirc 11, \square 27, \triangle 24,-22$ \\
\hline
\end{tabular}

For these Internet Surveys, the Yahoo!.Japan search engine was used as before. The output sites were visited quickly to find Site name, Site domain URL. The internal site search was carried out for all the sites, and the number of pages hit with the keyword TRIZ in the site was shown for each site. In the cases of survey of sites written in English, the sites were visited more closely and were evaluated tentatively in 5 grades; i.e., @ Most important in the World Catalog (i.e., about top 30), $\bigcirc$ Important in the World Catalog (i.e., about top 100), $\square$ Worthy in the World Catalog, $\triangle$ Worthy in Country Catalog, - Irrelevant/negligible. As you see in cases (2A) and $(2 \mathrm{~F})$, the output sites are (almost random) mixtures of very high to very low grades in their quality/relevance.

These results were posted in detail in THPJ [10] and sent to relevant people asking for their further work. Michael Orloff's reaction may be typical and important. He found the results for the Russian language sites (2B1) messy, and took a different 
approach as shown in (2B2). He listed up 26 Web sites of TRIZ professionals using his background knowledge, and also listed 49 users' sites/pages he recognized in various searches. Later, Nikolay Shpakovsky reviewed (2B1) and (2B2) and showed a revised list as in (3B3). Cases in other languages are under examination by the people in the relevant countries.

In May 2019, Nakagawa started the 3rd round Internet Surveys for extending the scope of methodologies wider around TRIZ. For such a purpose the choice of keywords is delicate and important. Results of initial trials are shown in Table 3 [11].

Table 3 Results of Internet Surveys in wider scopes of methodologies [11]

\begin{tabular}{|c|c|c|}
\hline Case & Keywords & Sites found (with evaluation) \\
\hline (3A) & Creat* Think* Method* & () $1, \circ 4, \square 15, \triangle 3,-84$ \\
\hline (3A2) & Creative Think Method & $\begin{array}{l}\text { ( ) } 1, \circ 15, \square 65, \triangle 31,-56, \\
\text { L (Listed already elsewhere) } 15 \text {. }\end{array}$ \\
\hline (3B) & $\begin{array}{l}\text { (Creative OR innovative OR Sys- } \\
\text { tematic) Problem Solve (Method } \\
\text { OR Process OR Technique) }\end{array}$ & $\begin{array}{l}\text { () } 10 \text { (L 8), } \bigcirc 26 \text { (L 7), } \square 64 \text { (L 7), } \\
\triangle 32 \text { (L 1), }-39\end{array}$ \\
\hline$(3 \mathrm{C})$ & $\begin{array}{l}\text { Innovation (Process OR Strategy } \\
\text { OR Method OR management OR } \\
\text { Technology) }\end{array}$ & $\begin{array}{l}\text { (○) (L 3), } \bigcirc 36 \text { (L 11), } \square 76 \text { (L 8), } \\
\triangle 70 \text { (L 0), }-19\end{array}$ \\
\hline (3D) & $\begin{array}{l}\text { (Quality OR Value OR Cost OR } \\
\text { Productivity) (Deploy OR Engi- } \\
\text { neering OR Management OR } \\
\text { Control OR Analysis) (Method } \\
\text { OR Technique OR Theory OR } \\
\text { Process OR "Case Study") }\end{array}$ & 223 (under examination) \\
\hline$(3 \mathrm{E})$ & $\begin{array}{l}\text { (Patent OR IP OR "Intellectual } \\
\text { Property") (Analysis OR Protect } \\
\text { OR Circumvent OR Mapping OR } \\
\text { Strategy) }\end{array}$ & 186 (under examination) \\
\hline
\end{tabular}

When a wild card * is used in the keywords (3A), the search engine interpreted it very widely, including the words: make, build, believe, way, etc. The keywords in cases (3A2) (3B) and (3C) seem to be productive. We have two more cases (3D) and (3E) of surveys, which seem useful but taking much time and efforts for examination.

\subsection{Proposal of WTSP Database System for Generating Categorized World WTSP Catalogs}

At the stage of late Mar. 2019, a few hundred of Web sites were expected to be shown in our World WTSP Catalogs. How should we categorize and arrange them in the Catalogs? Alphabetical order of the site names? Arranging by countries? In which ways users want to use the WTSP Catalogs? -- Considering these issues, we have found that users want to see the contents of WTSP Catalogs from multiple views of aspects. As such aspects we listed up Site location, Site language, Roles of the site (or site owner), Application phases, Application fields, Methodologies, and Evalua- 
tion. Thus it is desirable for us to be able to categorize and arrange hundreds of sites in these multiple views of aspects as requested by the users.

In late May 2019, Nakagawa proposed a conceptual design of WTSP Database System as illustrated in Fig. 3 [12].

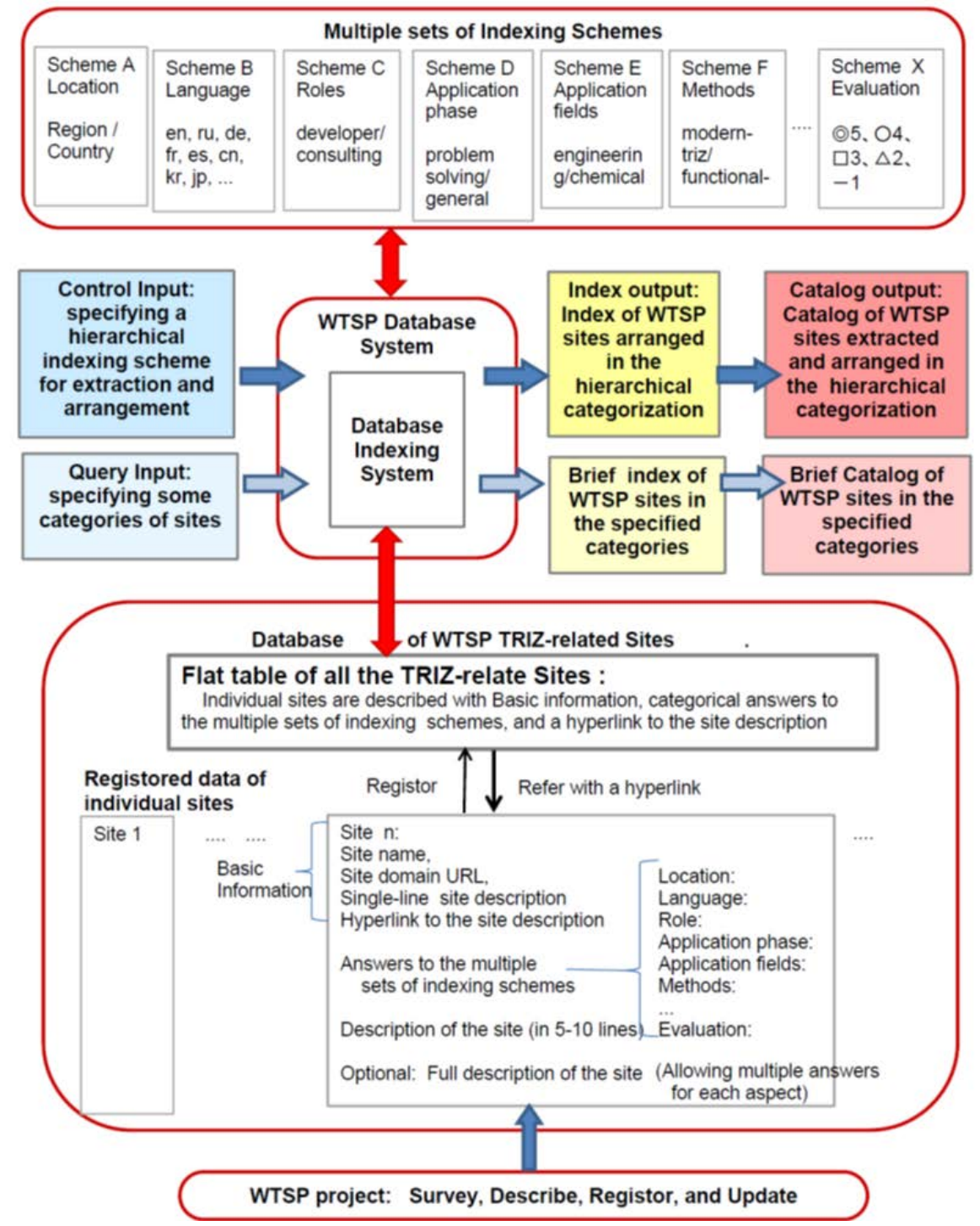

Fig. 3 Conceptual Design of WTSP Database System [12]

The system installs multiple sets of Indexing Schemes [13], or aspects of views, as shown at the top. It is important to set and define these schemes systematically yet practically. The data of individual sites should contain the information as shown at the bottom. All the sites registered in the database should have records in the Flat 
Table of all the sites, with the attributes of basic information, Answers to the multiple sets of indexing schemes, and hyperlink to the site description.

The system may be used as the WTSP Catalog Generator, where a user (or Catalog Editor) inputs the control specifying a hierarchical indexing scheme for extraction, categorization, and arrangement of sites. Then the Database Indexing System inside the WTSP Database system operates on the temporary copy of the Flat Table to select, categorize, and arrange the sites as specified, by using the function just like Excel's sorting algorithm. Thus the Index form of WTSP Catalog is output, and then the WTSP Catalog may be output by inserting the Description of the sites.

We should note that the WTSP Database System can also be used as an On-line Query System. Users request some categories of sites, and the System outputs Brief Index of WTSP sites in the specified categories, and Brief WTSP Catalogs of specified categories further.

Once this System is installed, the WTSP project can concentrate their efforts to survey, describe, register, and update the TRIZ-related sites in the world, because the system can generate World WTSP Catalogs semi-automatically with the registered data of sites.

\section{Practical Approaches for Completing the World WTSP Catalogs (since June 2019)}

\subsection{Reconsidering the difficulties}

As described so far, the WTSP project have developed the visions, guidelines, project teams, processes, methods, etc. step by step for building the Country and World WTSP Catalogs. However, our project is much behind the time schedule for completing the World WTSP Catalogs before TFC2019, to be held on Oct. 9-11, 2019. The weak point of our project is the fact that in many countries the WTSP Teams are not formed well and not working actively.

The problem situation is "Many people support the aims of the WTSP project, but very few actually join to work together". And the main reason for it is "Talented, active persons in TRIZ are always too busy”, as known from the beginning. Considering the reasons further, we have found the following points.

(a) The WTSP Database System is a proposal of an 'Ideal form', which is not feasible in a few months. We need to find some structure of the WTSP Catalogs, which is clear, practical, easy to build and update, and allowing integration of parallel works by many Teams of various countries.

(b) We need a prototype of World WTSP Catalogs. Japan WTSP Catalog [7] is for people in Japan and not appealing to people in the world. We need "World WTSP Catalog (Japan Part)” containing sites selected for the people in the world.

(c) Trying to make Country WTSP Catalogs with thorough survey is a heavy task in each country. At the stage of June 2019, we should change our basic strategy to focus our efforts on the World WTSP Catalogs, containing selected, smaller number of sites from various countries. 
(d) We have not seen actual image of the World WSP Catalogs yet. What kinds of sites are actually arranged in the $(0)$ and $\bigcirc$ levels. People want to see them, even in a rough draft. Thus, we should better apply the "20-80 Principle", i.e., "Do the rough but essential $20 \%$ efforts and get the $80 \%$ results”.

(e) On the basis of (a) to (d), we need to have a Practice Guide for the WTSP Teams in various countries to contribute actively to achieve the World WTSP Catalogs together. It should have step by step instructions to prepare for the manuscripts of their own parts of the World WTSP Catalogs.

(f) We should have two-step plan. A preliminary version of World WTSP Catalogs we should make first as a draft containing smaller number but important sites. Then we will make revised and enhanced versions of World WTSP Catalogs.

(g) Many TRZ colleagues, when they look at these visions and strategies, will be able to see their own tasks and feasibilities to achieve the WTSP goals meaningful for themselves as well as for the world.

All these new tasks and strategies have been pursued since June 2019, as described in the following sections.

\subsection{Structure of the World WTSP Catalogs, practical and useful}

Considering to make the 'ideal' WTSP System (Fig. 3) more practical and feasible without assuming a new automating system, we reached the structure shown in Fig. 4 [14].

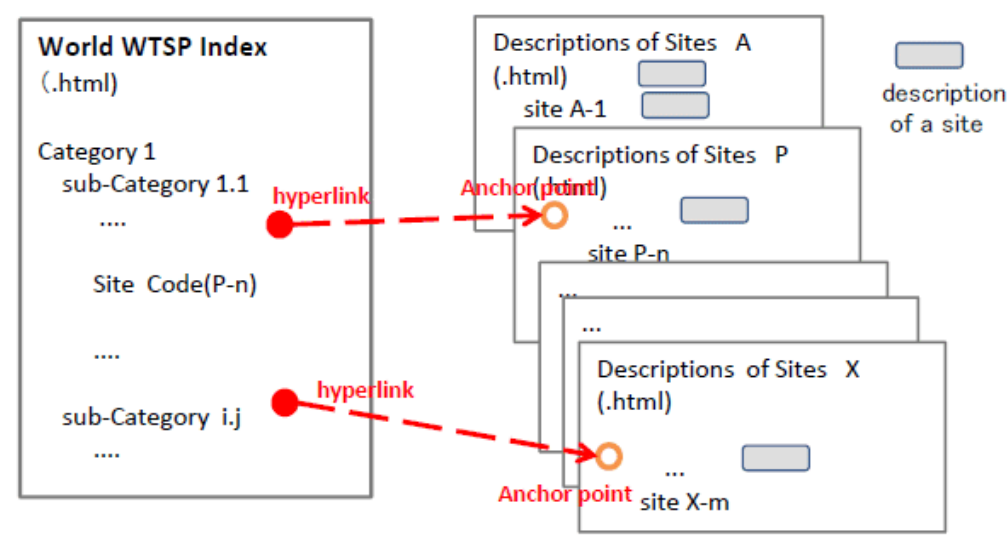

Fig. 4 Structure of the World WTSP Catalogs [14]

The right part of Fig. 4 is a simple collection of files of 'Descriptions of sites' submitted by various Teams. Each Team makes a Word file, where various sites may be written in the standardized tabular form or in more relaxed ways, and convert it into an HTML file.

The left part of Fig. 4 is the Index of the WTSP Catalog, which corresponds essentially to the 'Flat Table of all the sites' in Fig. 3. Individual WTSP Teams submit 'Flat Table of sites' in Excel, and all the tables are merged into one Flat Table. Then 
the Table is sorted and rearranged manually in Excel in various hierarchical ways, and is converted into an HTML page.

Each Team, before submission, should set hyperlinks from individual site in the 'Flat Table' to actual description of sites in the 'Descriptions of sites' file. Hyperlinks have a big advantage that their links are flexibly connected even though the sites are rearranged in any manner in the Flat Table (or the Index) or the site descriptions are rearranged in the 'Descriptions of sites' files. This structure also allows to revise and add site descriptions afterwards and to make multiple Catalog Indexes by rearranging the sites in the Flat Table in different ways.

The completed World WTSP Catalogs may be posted as a small Web site (and even delivered easily in a folder) containing one (or multiple) Index page(s) and many pages of site descriptions. Users may read the Index page of many sites arranged in some systematic manner, and may click any site to read some more details of the site. Users may also read the 'Descriptions of sites' pages, where sites are arranged in a manner the Team of a country or the editor of a top-down survey supposed best.

\subsection{World WTSP Catalogs (Japan Part) instead of Japan WTSP Catalogs}

All the 92 sites in Japan WTSP Catalog (i.e., WTSP Catalogs of TRIZ-related sites in Japan for the people in Japan) have been re-evaluated in the criteria of World WTSP Catalogs. The results [15] are summarized in Table 4.

Table 4 Sites to be included in World WTSP Catalog (Japan Part)

\begin{tabular}{|c|c|}
\hline Sites in TRIZ & Sites around TRIZ \\
\hline $\begin{array}{l}\text { (0) TRIZ Home Page in Japan } \\
\quad \text { (Toru Nakagawa) } \\
\text { Japan TRIZ Society (NPO) } \\
\text { IDEA Co. (Mamoru Zenko) } \\
\text { MOST LLC } \\
\quad \text { (Kazuya Yamaguchi) } \\
\text { Ideation Japan Ltd. } \\
\quad \text { (Teruyuki Kamimura) } \\
\text { TRIZ Study } \\
\quad \text { (Shinsuke Kurosawa) } \\
\text { Monodukuri.com } \\
\quad \text { (Osamu Kumasaka) } \\
\square \text { (Former) Japan TRIZ CB } \\
\square \text { Cybernet System Co. Ltd. } \\
\square \text { Pro-Engineers } \\
\quad \text { (Shigeru Kasuya) } \\
\square \text { Idea Plant (Rikie Ishii) } \\
\square * \text { MEMODAS } \\
\quad \text { (Kimihiko Hasegawa) }\end{array}$ & $\begin{array}{l}\text { O* Idea Marathon Institute (Takeo Higuchi) } \\
\square \text { J-STAGE (JST) } \\
\square \text { Daiichi Kousha (Akihiro Katahira) } \\
\square * \text { Netman (Ken-ichi Nagaya) } \\
\square * \text { JST (Japan Science \& Technology Agency) } \\
\square * \text { NEDO (New Energy and Industrial } \\
\text { Technology Development Organization) } \\
\square * \text { Japan Creativity Society } \\
\square * \text { JUSE (Union of Japanese Scientists \& } \\
\text { Engineers) } \\
\square * \text { JSQC (Japanese Society for Quality Control) } \\
\square * \text { SJVE (Society of Japan Value Engineering) } \\
\square * \text { JIII (Japan Institute of Invention and } \\
\text { Innovation) } \\
\square * \text { JAIST (Japan Advanced Institute of Science } \\
\text { \& Technology) } \\
\square * \text { i.school, The University of Tokyo } \\
\square * \text { Keio SDM, Keio University Graduate School }\end{array}$ \\
\hline
\end{tabular}


The sites in the left column are more or less specialized in TRIZ. They include 1 ( ) site, $6 \bigcirc$ sites, and $5 \square$. They are mostly TRIZ promotors and consultants. The sites in the right column are related to the methodologies around TRIZ, in the sense that they share nearly the same interests and goals with TRIZ. Most of them are national governmental organizations, academic or professional associations of methodologies close to TRIZ, and universities with special research/teaching activities in the field of creative thinking.

The * marks mean that they are not selected in the 24 sites in the Japan WTSP Catalogs. Among the 24 selected sites in the Japan WTSP Catalog, 11 sites will not be shown in the World WTSP Catalogs. Many of them were active in '90s and '00s but not much in '10s. And 3 knowledge-sharing sites. i.e., Wikipedia, YouTube, and Slides Share, are also dropped because they are certainly shown as (O) sites in the World WTSP Catalogs principally based in USA.

\subsection{Practice Guide for preparing WTSP Catalogs in various countries}

The new Practice Guide was first written in early June and revised little by little until mid-July [14]. It describes how to form WTSP Teams and how to prepare the manuscripts of the World WTSP Catalogs. The basic points are described below along the process.

(1) To get people as voluntary WTSP Members and form WTSP Team with a coordinator

This is the initial step of our process. Even though we meet much difficulty at this step in many countries, we need to keep trying various activities, as discussed so far. They include:

You are invited to understand the aims, visions, significance, importance, etc. of the WTSP project, by referring to our Appeal [5] and Summary slides [3].

You may look at the prototype examples of WTSP Catalogs, such as World WTSP Catalog (Japan Part) [15] and some others coming soon, and compare them with some simple lists of TRIZ links and also with messy/noisy outputs of internet surveys. You may learn many interesting examples of sites in the WTSP Catalogs which were not known much so far. Then you might realize the importance of introducing good TRIZ-related sites in your own country to the people in the world.

You may study the structure of WTSP Catalogs and the basic process for listing up the sites and describing the site introductions [14]. Then you might understand that the tasks for you (and your TRIZ colleagues in your country) is to make the manuscripts of your Country Part of World WTSP Catalogs and that such tasks can be achieved in cooperation with your TRIZ colleagues in your country without so much burdens.

Then you would eventually find that the merits and significance of contributing to the World WTSP Catalogs by making manuscripts of your Country Part is certainly greater than the efforts and time you need to spend for making the manuscripts. At such a stage you are welcome to join WTSP together with your colleagues and form a WTSP Team for your country. 
You would naturally agree that a group of several people need a coordinator for working effectively in cooperation. In WTSP, Country Editor plays the role of a coordinator. The coordinator must understand the vison, tasks, processes, etc., and coordinate the members in their work, i.e., dispatch various tasks to the members and integrate the results by the members, etc. Since WTSP is operated entirely on a volunteer basis, getting a Country Editor is most important for the activities in each country.

(2) List up candidate sites, by recommendations and by Internet surveys

An easy and best way to list up candidate sites is getting recommendations from many TRIZ colleagues in your country. Using a template in our Practice Guide [14], list up a number of candidate sites by the Team members and send the list to other keypersons as widely as possible, asking them to list up some more. This process is usually good enough for listing up candidate sites to be included in the World WTSP Catalogs.

If you want to find useful TRIZ-related sites thoroughly, e.g., to make a complete Country WTSP Catalogs, you need to make Internet surveys. When you make a survey, using the keyword TRIZ for example, you will find that the search engines produce a flood of information, which is messy and noisy and hiding useful information. A lot of experiences and obtained knowhow are described in Nakagawa's reports [811]. Because of so much noise in the Internet searches, WTSP members in many countries were discouraged so much and quitted/postponed their WTSP activities. This is the biggest reason for our failure in the initial Bottom-up Approaches, i.e., to make thorough Country Catalogs and then go to (Country part of) World Catalog with selected sites. Thus we recently shifted our strategy to make efforts for building the World WTSP Catalogs first, with the manuscripts from countries containing the sites recommended highly as explained above.

(3) Describe individual sites, either by the site owners or by other surveyors

Now we should describe individual sites one by one as the manuscripts to be shown in the WTSP Catalogs. We may use the template of Site Description posted in the Practice Guide [14].

It is best to get the site owner fill in the template. The mandatory information is Site name, Site domain URL, Site location, Site language, Roles of site, Evaluation, and (most desirably) Description of introduction. Sometimes an organization/company operates their sites in multiple countries, in multiple languages, and hence with different URLs and different site names; in such cases we may show the representative one(s) as the site in the World WTSP Catalog, with information of subsidiary sites attached. Roles of site should be expressed according to the codes specified in the 'Multiple sets of Indexing Schemes' shown in [13]. Typical roles may be: (a1) Dedicated for information sending, (e1) Method developers, (e4) Consultants, (g3) Knowledge sharing, etc. Description of introduction may be written in free format in about 3 to 10 lines.

In cases when we need to describe any site, it takes much time for us to visit the site to understand it and describe it concerning to the items in the standard format. You may learn Nakagawa's experiences and know how [8-11, 14]. Typically, we visit a page of the site (with the key of Internet search output), then go to the top pag- 
es, ‘About us` pages, and a number of principal pages. Carrying out a site search (i.e., Internet search of relevant pages inside a specified site) is useful. Excerpts from top pages and 'About us' pages may be useful as a quick alternative of the site introduction. Evaluation of the site is a delicate job, but necessary even as a tentative one for us to proceed to build WTSP Catalogs. For only the sites with evaluation $\bigcirc \bigcirc \square$, we should describe the site closely.

(4) Making 'Flat Table of sites' as the manuscript of World WTSP Catalogs

You gather the descriptions of sites of high evaluation $(\bigcirc \bigcirc \square)$ in a Word file. And you make a 'Flat Table of sites', using the template in Excel shown in [14]. Basic information of site in the standard format can be used to fill in. Site code is a numbering given to the sites in some proper way for managing the sites, and a hyperlink is set with it for referring to the site description. (Note that numbering itself is not so important because the sites are rearranged in the WTSP Catalogs in various ways by use of other items in the Flat Table.)

(5) Build and check Your Part of World WTSP Catalog as a small Web site

You now convert your 'Flat Table of sites' file and 'Descriptions of sites' file into HTML (i.e., Web pages). Then at the beginning of each site description, set an anchor point having the ID of the Site code. Put the two pages in a folder and test that every hyperlink in the Flat Table (i.e., Index) page jumps to the proper description of sites. In this manner, you now have a small Web site of Your Part of World WTSP Catalog.

(6) With your manuscripts the World WTSP Catalogs are now completed

You should submit your Flat Table file in Excel and Descriptions of Sites file in HTML to the WTSP Project. Integrating many such parts, World WTSP Catalogs can be built as shown in Fig. 4. The results of top-down Internet surveys will also be important parts of the World WTSP Catalogs. Handling duplications of sites in many manuscripts of parts may be a tedious issue. It is possible to make multiple sets of Index of World WTSP Catalogs by simply using different sorting of sites in the Flat Table.

\subsection{Plans of Preliminary and Completed World WTSP Catalogs}

On the basis of our new strategy (especially based on the "20 - $80 \%$ principle") described so far, we have just announced our concrete 2-step plans as follows:

(A) First Preliminary version of World WTSP Catalog:

Containing sites evaluated as $\bigcirc \bigcirc$ only.

Manuscripts due: Jul. 28, 2019; Completion/Posting: Aug. 4, 2019;

(B) Second (and last) Preliminary version of World WTSP Catalog:

Containing sites evaluated as $\bigcirc \bigcirc \square$.

Manuscripts due: Sept. 15, 2019; Completion/Posting: Sept. 30, 2019

In the current situations of WTSP Teams in many countries, we expect not so high quality in (A), but after people see it they will contribute to make (B) much improved.

After the presentation and discussions at ETRIA TFC2019 and reviewing (B) closely, we should better complete the World WTSP Catalogs:

(C) First Edition of the World WTSP Catalogs (2019): 
Containing sites evaluated as $\bigcirc \bigcirc \square$.

Manuscripts due: Nov. 15, 2019; Completion/Posting: Dec. 10, 2019

\section{$5 \quad$ Concluding Remarks}

\subsection{Necessity of Collaboration of Human work}

As described so far, the WTSP project has been working to show the visions and their significance, the structure and its building process, prototypes and actual processing, etc. and to convince TRIZ colleagues to work together. It is clear we still needs some more time for getting voluntary contributions by many people.

We would like to mention again the basic points of needing collaboration.

Because of language barriers and necessity of handling a huge amount of information, any person can survey only some limited range of Web sites for durable spending of time and efforts. It is the first responsibility for the site owners and then the people in the same country to introduce their sites. Even they did so, editors and writers of the World WTSP Catalogs can visit, understand, and evaluate only some portions of sites in the Catalogs. Thus, it is very delicate to be fair in selecting, introducing, and evaluating all the sites in the World WTSP Catalogs. Cooperative work by many people in the preparation is of course necessary. Reviews by many people and suggestions/recommendations by them need to be reflected in the revision process. This implies that the quality and usefulness of World WTSP Catalogs can be improved only by keeping update with global cooperation.

For avoiding the hard tasks in surveying, describing, and evaluating many sites, some people suggest to use AI or software robots. But we should realize that the current difficulty of surveying significant sites comes from the poor quality in the Internet surveys. Unfortunately, the current software technology (including AI) can't make introduction of a site with satisfactory quality and can't select good sites in a topic. The flood of messy/noisy outputs of internet surveys shows us we can't use AI at moment. We should better rely on our colleagues' professional ability for describing site introduction and selecting good sites.

Thus it is clear that getting good voluntary members and especially good Country Editors is most crucial for the success of our WTSP Project.

\subsection{TRIZ Spirits in the WTSP Project}

We believe that our WTSP Project has its basis on the TRIZ Spirits. Namely,

(a) To have a vision, to overcome difficulties one by one, and to achieve the goal.

(b) To divide the tasks appropriately and to divide the systems appropriately as well, in order to build the overall system functioning effectively, and consequently to make the work by all the cooperating people fruitful.

(c) To build the Catalogs of Web sites in the whole world in the areas of TRIZ and related methodologies, to connect the activities, accumulated knowledge, and results 
by the huge number of people working in such areas, and to form a basis for developing and proliferating such methodologies further in mutually cooperating ways.

(d) To promote the project by relying on the passion of those people in the world who are inspired with TRIZ and holding TRIZ as their important guiding principle.

\section{References}

1. Nakagawa T., Mann D., Orloff M., Dewulf S., Litvin S., Souchkov V., World TRIZ Sites Project (WTSP) for Building and Maintaining Global Catalogs of TRIZ-related Web Sites, Presented at ETRIA TRIZ Future Conference 2018, held on Oct. 29-31, 2018, at Strasbourg, France; posted in THPJ, http://www.osakagu.ac.jp/php/nakagawa/TRIZ/eTRIZ/epapers/e2018Papers/eNaka-WTSPTFC2018/eNaka-WTSP-TFC2018-181108.html, posted 2018/11/11

2. Nakagawa T., World TRIZ Sites Project: Its Plan and Invitation: Volunteer Project for Connecting TRIZ Sites in the World, THPJ, http://www.osakagu.ac.jp/php/nakagawa/TRIZ/eTRIZ/eforum/e2017Forum/eNakaWorldTRIZSitesProject2017/eNaka-WTSP-Invitation-171207.html, posted 2017/12/9

3. Nakagawa T., Mann D., Orloff M., Dewulf S., Litvin S., Souchkov V., World TRIZ Sites Project (WTSP) for Building and Maintaining Global Catalogs of TRIZ-related Web Sites, Summary slides of ETRIA TFC2018 presentation, Oct. 31, 2018; THPJ, https://www.osaka-gu.ac.jp/php/nakagawa/TRIZ/eTRIZ/epapers/e2018Papers/eNakaWTSP-TFC2018/eNaka-WTSP-TFC2018-Summary-4P-181023.pdf, posted 2018/11/11

4. Nakagawa T. editor, “TRIZ Home Page in Japan”, https://www.osakagu.ac.jp/php/nakagawa/TRIZ/eTRIZ/, established on Nov. 1, 1998.

5. Nakagawa T., Mann D., Orloff M., Dewulf S., Litvin S., Souchkov V., WTSP Appeal: An Appeal for Building Catalogs of TRIZ-related Sites in the World, THPJ, http://www.osaka-gu.ac.jp/php/nakagawa/TRIZ/eTRIZ/eWTSP/eWTSP-B2News2018/eWTSP-News2018-Appeal-180625.html, posted 2018/6/25

6. Nakagawa, T., Extended 120 TRIZ Links in the World, THPJ, http://www.osakagu.ac.jp/php/nakagawa/TRIZ/eTRIZ/elinksref/eWorldLinks.html, posted 2008/5/4

7. Nakagawa T., Catalog of TRIZ-related Sites in Japan, THPJ, http://www.osakagu.ac.jp/php/nakagawa/TRIZ/eTRIZ/eWTSP/eWTSP-Outputs/eWTSP-D-jpJapan/eWTSP-D-jp-Japan.html, posted 2018/4/24

8. Nakagawa T., Starting the preparation of 'A Catalogue of TRIZ-related Sites in the World', (1) Findings through Practices in Japan, (2) For more practical ways of preparation, THPJ, https://www.osaka-gu.ac.jp/php/nakagawa/TRIZ/eTRIZ/eWTSP/eWTSP-B2News2018/eWTSP-News2018-Trial-Japan1-180127.html, posted 2018/1/30, 2018/2/7

9. Nakagawa T., Preliminary Internet Searches of TRIZ-related Sites in Various (33+) Countries, THPJ, https://www.osaka-gu.ac.jp/php/nakagawa/TRIZ/eTRIZ/eWTSP/eWTSP-B2News2018/eWTSP-News2018-PreliminarySearch-180919.html, posted 2018/9/21, 2018/9/27

10. Nakagawa T., Preliminary Internet Searches (2) of TRIZ-related Sites in the world, THPJ, https://www.osaka-gu.ac.jp/php/nakagawa/TRIZ/eTRIZ/eWTSP/eWTSP-B3News2019/eWTSP-News2019-PreliminarySearch-2nd-190328.html, posted 2018/3/18, 2018/3/31

11. Nakagawa T., Preliminary Internet Searches (3) of TRIZ-related Sites in wider scopes in the world, THPJ, https://www.osaka- 
gu.ac.jp/php/nakagawa/TRIZ/eTRIZ/eWTSP/eWTSP-B3-News2019/eWTSP-News2019PreliminarySearch-3rd-190516.html, posted 2019/5/18

12. Nakagawa T., Proposal of the WTSP Database System for the World TRIZ-related Sites Project (WTSP), THPJ, https://www.osaka-

gu.ac.jp/php/nakagawa/TRIZ/eTRIZ/eWTSP/eWTSP-DatabaseSystem/eWTSP-

DBSystem-Proposal-190522.html, posted 2019/5/24

13. Nakagawa T., Multiple Sets of Indexing Schemes for the WTSP DB System, THPJ, https://www.osaka-gu.ac.jp/php/nakagawa/TRIZ/eTRIZ/eWTSP/eWTSP-

DatabaseSystem/eWTSP-DBSystem-IndexSchemes-190522.html, posted 2019/5/24

14. Nakagawa T., Practice Guide to Complete the World WTSP Catalogs and to Report It at ETRIA TFC2019, THPJ, https://www.osaka-gu.ac.jp/php/nakagawa/TRIZ/ eTRIZ/eWTSP/eWTSP-B3-News2019/eWTSP-News2019-PracticeGuide-Jun2019190607.html, posted 2019/6/14

15. Nakagawa T., World WTSP Catalogs (Japan Part): WTSP Catalog of TRIZ-related Sites in Japan for the people in the whole world, THPJ, THPJ, https://www.osakagu.ac.jp/php/nakagawa/TRIZ/eTRIZ/eWTSP/eWTSP-Outputs/eWTSP-D-jpJapan/eWTSP-World-D-jp-Japan.html, posted 2019/7/14 